\title{
International Journal of Engineering
}

Journa l Ho m e pag e: w w w. i je.i r

\section{Multi Objective Optimization of Multi-hole Orifices using Fluid-solid Interaction Analysis and Multi-objective Genetic Algorithm}

\author{
M. Taheria, A. Mahdavia,b, H. Safikhani*a \\ a Department of Mechanical Engineering, Faculty of Engineering, Arak University, Arak 38156-88349, Iran \\ ${ }^{b}$ Department of Mechanical Engineering, 5-8 F Mech. Eng. Building, University of Alberta, Edmonton, AB, T6G $2 G 8$ Canada
}

\section{$P A P E R \quad I N F O$}

\section{Paper history:}

Received 22 April 2021

Received in revised form 14 May 2021

Accepted 29 May 2021

\section{Keywords:}

Multi-hole Orifices

Pressure Drop

Fluid Solid Interaction

Multi-objective Optimization

Sensitivity Analysis

\section{$A B S T R A C T$}

Multi-hole orifices have better performance than single-hole orifices. In this paper, multi-objective optimization of multi-hole orifices is performed using a Fluid-Solid Interaction (FSI) analysis and multiobjective genetic algorithm (NSGA II). In all numerical analysis, the governing equations of the solid and the governing equations of the fluid are carried out for orifice and fluid around orifice, respectively. All calculations are made for a 16-hole orifice with circular holes. The design variable in the optimization process is the distance between the holes of the orifice and thus the amount of shrinkage or expansion of the orifice geometry. The objective functions are the pressure drop created on the sides of the orifice, the deformation and tension created in the orifice structure, which should be maximized, minimized and minimized, respectively. In the results section, the Pareto front are presented which represent useful information for designing the multi-hole orifices geometry, and five orifices are also introduced as final design options that have better performance. The results of the sensitivity analysis of the various parameters are also presented and discussed in detail in the multi-hole orifices.

\section{INTRODUCTION}

Orifice is a device for measuring the mass flow rate of fluid flow, which is a flat metal plate with one or more holes and is installed perpendicular to the flow direction. When the fluid passes through the orifice, due to the decrease in cross-section, its velocity increases and its pressure decreases. For different sizes of the orifice plates, there is a direct relationship between the current flow through the orifice plate and the pressure drop due to the flow through the orifice plate. The orifice plate usually has a thickness of about 1.61 to 1.4 inches, and is usually positioned between two flanges interfaced with two metal seals, and according to the diameter that is in plate, they pass through a range of mass flow rates of fluids. Figure 1 shows the location of the orifice in the pipeline, and also shows how to calculate the mass flow rates in the presence of orifice.

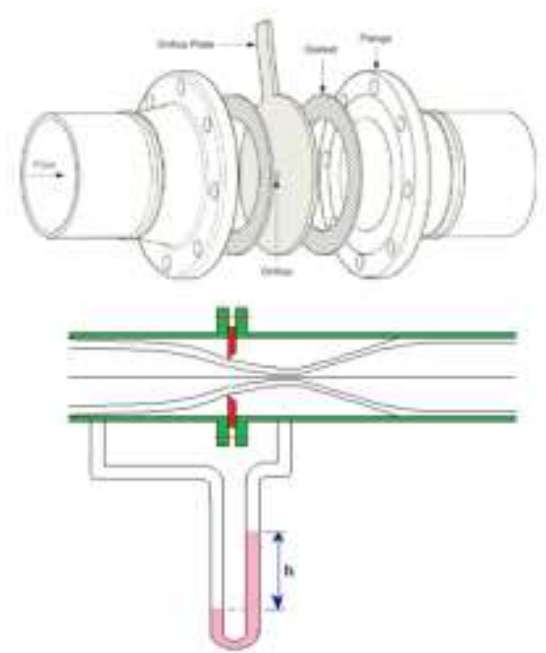

Figure 1. The location of orifice and the general overview of the fluid transition from orifice

*Corresponding Author Institutional Email: h-safikhani@araku.ac.ir (H. Safikhani) 
When the flow passes through the plate, its pressure suddenly drops and this pressure drop continues to the area called the lowest pressure (Vena Contracta). After passing through this area, the flow pressure gradually increases and after a distance of about 5 to 8 times the the downstream area. Reducing fluid pressure during the passing through the orifice is because of increased velocity in this area, and when the velocity starts to decrease, the pressure begins to increase in proportion to this decrease.

For the first time, the Italian physicist Juan Venturi used a pressure drop system to measure flow rates in 1797, which resulted in the development of a more modern Venturi measuring system by Clemens in 1886 and from 1924 to 1935, laboratory experiments were carried out by the American Gas Association and the American Society of Mechanical Engineers (ASME) to develop the orifice measurement systems for coefficients and installation standards. Finally, in 1935, these two associations jointly published a report entitled calibration history, installation and performance of orifice measurement systems and in 1991, the American Petroleum Institute (API) published the standards for the measurement of petroleum in Chapter 14, Part 3, in terms of pressure difference method [1]. Krou and Sowa [2] optimized the geometry of orifices for the flow of mixtures in a cylinder in terms of the number of orifices, hole diameter, and angle of the holes of the orifice using experimental results. But, the behavior of the orifices has not been investigated in simulation and numerical solution. Also, the experimental results are not verified by numerical solution. Zhang and Bodony [3] reviewed numerical and linear acoustic modeling of flow in orifice to reduce noise by numerical solution using Navier Stokes equations and also using Fourier's law in heat transfer. Badr et al. [4] predicted the dynamical behavior of the flow of some orifices by calculating the fluid dynamics using the vortex viscosity model k- $\varepsilon$. The flow characteristics were predicted and the effect of different parameters such as flow velocity and erratic distance they made it and the effects of various parameters such as flow velocity and distance of orifices were investigated. Gan and Riffat [5] conducted a study on the characteristics of pressure drop in perforated orifices and plates. They conducted experiments to determine the pressure drop for a thin plate in a square duct for a number of Reynolds numbers and investigated the effect of plate thickness on pressure loss for orifices using Computational Fluid Dynamics (CFD). Zhao and Zhang [6] presented a general structural design method for multi-hole orifices and its empirical application and said that in comparison to single-hole and multi-hole orifices, single-hole orifices have smaller sizes and different patterns of geometric shapes and are more complex. This method first introduces a comprehensive set of geometric architectures that include the orifice setup criteria and geometric parameters such as the total number of orifice, the density of the distribution of orifice, and the equivalent diameter ratio. They investigated a series of different experiments with water flow to study the effect of different geometric properties on the pressure drop and finally presented an optimal model. Simpson and Ranade [7] presented results of computational investigation into cavitation in different orifice designs over a range of operating conditions. Rainsford et al. [8] presented highspeed photography to visualize fast-flame and detonation propagation through a transparent round tube equipped with repeating orifice plates, in stoichiometric hydrogenoxygen mixtures at initial pressures up to $60 \mathrm{kPa}$. Yu et al. [9] presented experimental and numerical research on the internal flow and spray behaviors with biodiesel for elliptical orifice with large aspect ratio and circular orifice of diesel nozzles, under high injection pressure and backpressure conditions. Zhao and Zhang [10] investigated the influences of supply pressure, orifice diameter, film thickness and pressure ratio on the pressure depression. Shan et al. [11] investigated the effects of the orifice to pipe diameter ratio (defined as the $\beta$ ratio) on the flow field behind a thin circular squareedged orifice plate. Moreover, some other researchers have studied about geometry of orifices [12-14], physical parameters of orifices [15-17], optimal conditions of orifices [18-21] and different algorithms for optimization methods [22-25] and numerical methods [26-28].

Based on available information, multi-objective optimization of multi-hole orifices in the form of a combination of FSI analysis and NSGA II algorithm has not been done so far. In this paper, multi-objective optimization of multi-hole orifices is performed using a Fluid-Solid Interaction (FSI) analysis and multiobjective genetic algorithm (NSGA II). In all numerical analysis, the governing equations of the solid and the governing equations of the fluid are carried out for orifice and fluid around orifice, respectively. All calculations are made for a 16-hole orifice with circular holes. The design variable in the optimization process is the distance between the holes of the orifice and thus the amount of shrinkage or expansion of the orifice geometry. The objective functions are the pressure drop created on the sides of the orifice, the deformation and tension created in the orifice structure, which should be maximized, minimized and minimized, respectively. In the results section, the Pareto front are presented which represent useful information for designing the multi-hole orifices geometry, and five orifices are also introduced as final design options that have high performance.

\section{DESIGN VARIABLES AND OBJECTIVE FUNCTIONS}

The orifice examined in this paper is a multi-hole orifice with 16 circular holes, shown in Figure 2. 


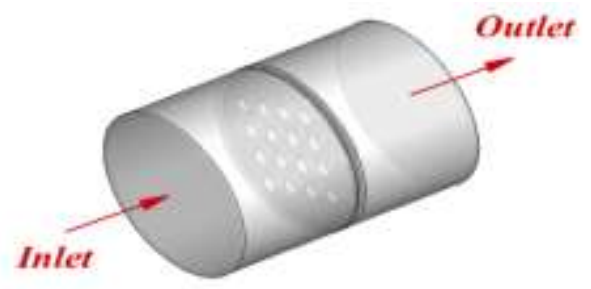

Figure 1. Overview of the 16-hole orifice and the fluid passing through it

The only design variable for optimization in this paper is the gap between the two holes of the orifice. The orifice geometry, as shown in Figure 3, is bounded in such a way that all the horizontal and vertical distances of the orifice holes are equal. Therefore, the orifice can be opened or folded symmetrically in an optimization process.

The objective functions are the pressure created on the sides of the orifice, the deformation and tension created in the orifice structure, which should be maximized, minimized and minimized, respectively.

Flowchart of MOO process is depicted in Figure 4.

\section{NUMERICAL MODELING}

3. 1. Grid Generation Due to the FSI analysis, the grid should be produced for separate fluid and solid. Figure 5 shows the view of the generated grid. It has been attempted to produce the best and most high-quality grid after conducting the grid independency test, especially in areas with high gradients. By changing the design variable, the grid can automatically adapt itself to the new geometry in the optimization process. There are approximately 800,000 elements in the produced grids.

3. 2. Governing Equations The flow of fluid in the pipes is mainly turbulent. The governing equations in the turbulent flow in the fluid are as follows:

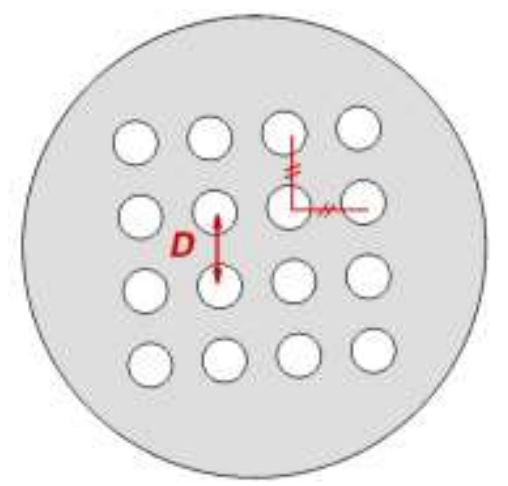

Figure 3. The distance between two orifice holes as an optimization design variable

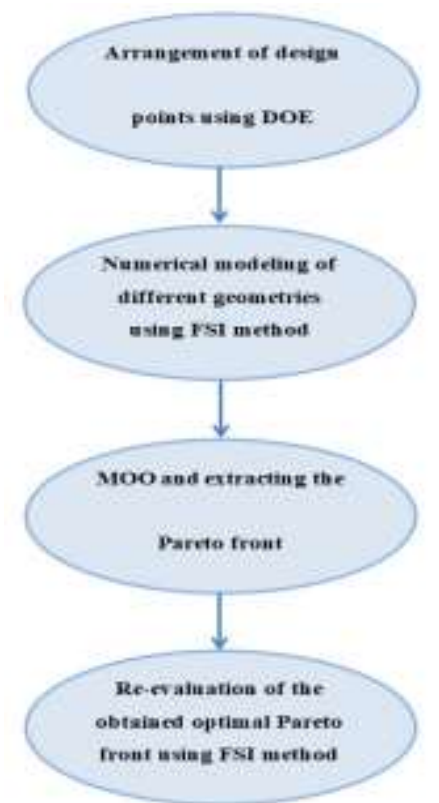

Figure 2. Flowchart of MOO process

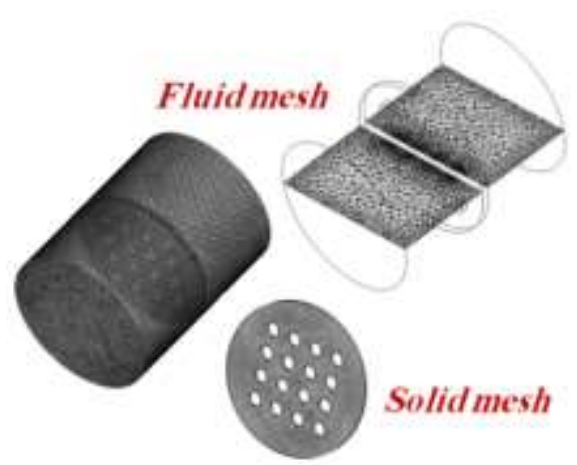

Figure 3. Mesh generation in FSI analysis

Continuity:

$$
\nabla \cdot(\rho V)=0
$$

Momentum:

$$
\nabla \cdot(\rho V V)=-\nabla p+\nabla \cdot\left(\tau-\tau_{t}\right)+\rho g
$$

Kinetic energy of turbulence:

$$
\nabla \cdot(\rho V k)=\nabla \cdot\left[\left(\mu+\frac{\mu_{t}}{\sigma_{k}}\right) \nabla k\right]+G-\rho \varepsilon
$$

turbulence loss rate:

$$
\nabla \cdot(\rho V \varepsilon)=\nabla \cdot\left[\left(\mu+\frac{\mu_{t}}{\sigma_{\varepsilon}}\right) \nabla \varepsilon\right]+\frac{\varepsilon}{k}\left(C_{1} G-C_{2} \rho \varepsilon\right)
$$

3. 3. Boundary Conditions Mass flow rate and the turbulence rate are specified at the inlet of the orifice, and there is a specific pressure at the output. The wall boundary condition is also used in walls. Fluid and solid 
exchange data for the calculation of tension and displacement of the wall.

\section{RESULTS}

In this paper, multi-objective optimization of multi-hole orifices performance is performed using a FSI analysis and multi-objective genetic algorithm. In this section, the associated results, including the Pareto front, are presented. The optimization process can be expressed mathematically according to the following equation:

$$
\begin{cases}\text { Maximize } & \Delta P=f_{1}(D) \\ \text { Minimize } & \sigma=f_{2}(D) \\ \text { Minimize } & \varepsilon=f_{3}(D)\end{cases}
$$

To validate numerical simulations, various data including pressure drop with the standard governing orifice, which is ISO 5167, were compared and a good agreement was observed with an error of less than $9 \%$. Therefore, numerical simulations can be used to carry out a multi-objective optimization process of multi-hole orifices. Pressure drop contour in fluid and deformation and stress contour in the structure are shown in Figure 6 as a sample of numerical simulations performed.

After 250 numerical simulations, as shown in Figure 7 , the Pareto front showing changes in pressure drop and deformation is shown in Figure 8. As is clear, all the results representing an independent and unique orifice, are completely non-dominate to each other, and when moving from an orifice to another orifice, one of the objective functions gets better and the other gets worse. In Figure 8, five points have unique characteristics. As shown in Figure 9, the front section of the deformation of the orifice is shown for points $A$ to $E$. Orifices have the minimum and maximum deformation in $A$ and $E$, respectively. Also for more recognition on the flow field, the way of fluid passing is shown in Figure 10 from 16hole orifice for points $A$ to $E$.

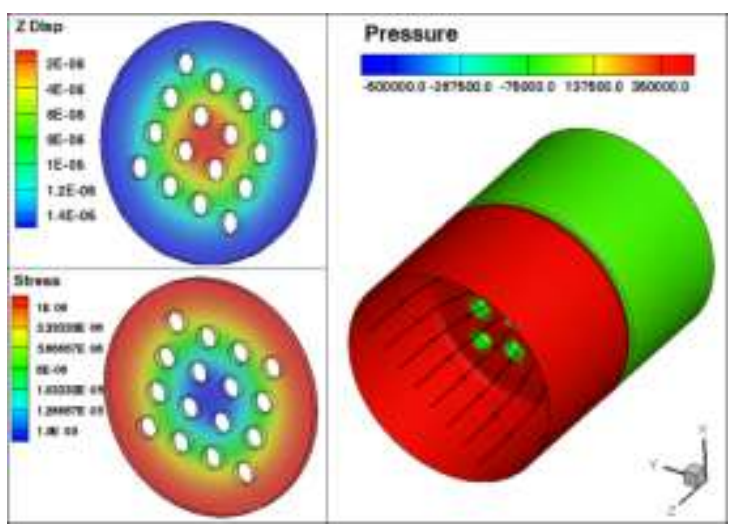

Figure 6. A sample of deformation and tension contours in the orifice and pressure drop in the fluid in a 16-hole orifice

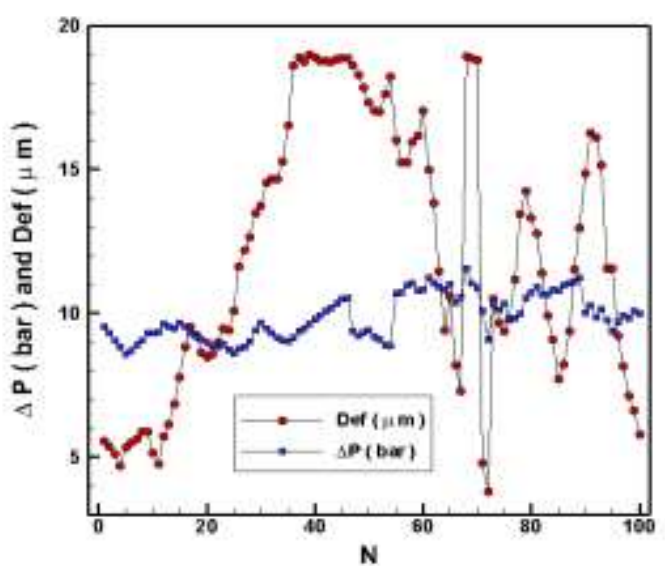

Figure 4. Sample of 250 numerical simulations performed in the multi-objective optimization process

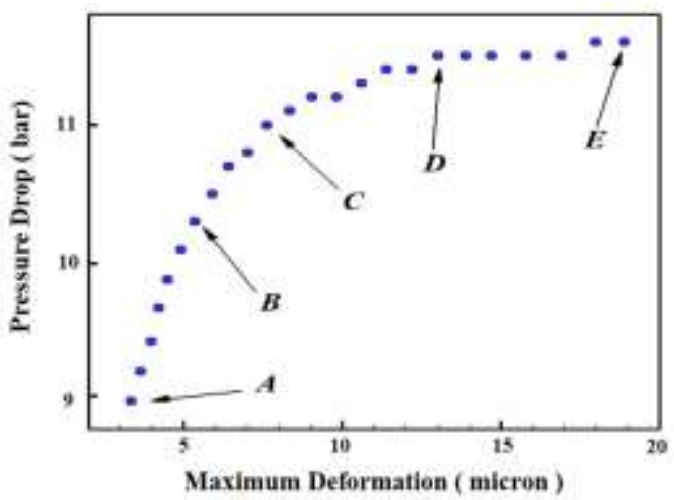

Figure 5. Pareto front: pressure drop vs. maximum deformation

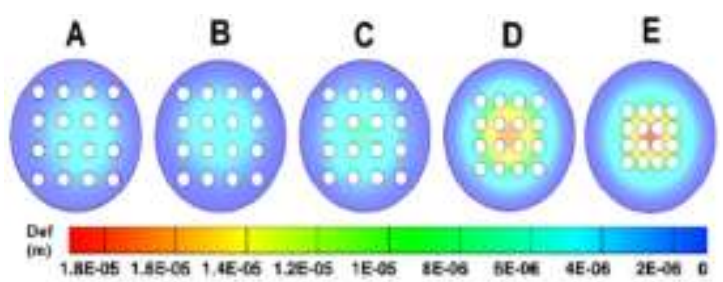

Figure 6. Deformation contour for the five points indicated in the Pareto front

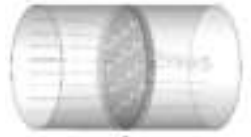

A

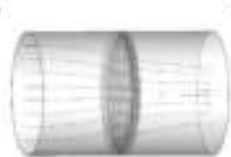

D

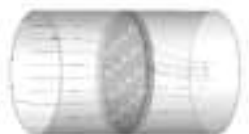

$\mathbf{B}$

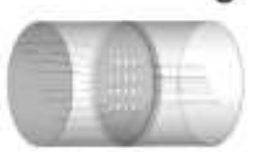

E
C

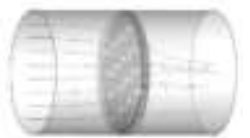

Figure 10. Fluid flow from orifice for the five points indicated in the Pareto front 
In Figure 8, the design points $A$ and $E$ stand for the best $\varepsilon$ (strain and deformation) and the best $\Delta P$ respectively. Moreover, the other optimum design points, $B$ and $D$ can be simply recognized from Figure 8 . The design point, $B$ presents important design concepts. In fact, optimum design point $B$ obtained in this paper exhibits an increase in deformation (about 12.3\%) in comparison with that of point $A$ whilst its pressure drop improves about $43.9 \%$, similarly optimum design point $D$ exhibits a decrease in pressure drop (about 8.2\%) in comparison with that of point $E$ whilst its deformation improves about $38.3 \%$. Points $B$ and $D$ which known as break points can only be identified by the multi-objective optimization approach used in this paper.

There are some interesting design facts which can be used in the design of multi-hole orifices. It is clear from these figures that $D$ is constant from points $A$ to $B$ and from $D$ to $E$ and varies with quadratic relation between points $B$ and $D$. These useful relationships that indefeasible between the optimum design variables of multi-hole orifices cannot be discovered without the use of multi objective Pareto optimization process presented in this paper. It is now ideal to find optimal design points that are compatible with both functions. This can be achieved by the method employed in this study, namely, the mapping method [23]. In this method, the values of objective functions of all Pareto points are mapped range 0 and 1 . Using the sum of these values for each Pareto point, the trade-off point simply is one having the minimum sum of those values. As a result, optimum design point $C$ is the trade-off points which have been obtained from this method.

In a post CFD investigation, the design points of the Pareto front obtained by the optimization process are reevaluated by CFD. The results of such CFD analysis reevaluations have been compared with those of numerical results using the optimization method in Table 1. As seen the optimization process agree well with the CFD results with error less than 3\%. This shows the accuracy of the optimization process from start to the end.

The Pareto front obtained from the optimization process (Figure 8) is mounted with the corresponding CFD simulation results in Figure 11. From this figure it is clear that such a Pareto front is the best possible combination of CFD data target values, which shows the effectiveness of this paper in obtaining the Pareto front.

Figure 12 shows the sensitivity analysis of the distance between the orifice holes on the functional functions of the orifice, such as pressure drop, deformation, tension and strain. As it is known, the highest sensitivity among the functional functions is the tension and strain and the low sensitivity is the pressure drop.

In the results section, the Pareto front, which represent useful information for designing the multi-hole orifice's geometry, were presented, and five orifices that have better performance are also presented as final design options, with details of their flow in Table 2 and their figures were shown in Figures 8 and 9. The design points $A$ and $E$ were stand for the best $\varepsilon$ and the best $\Delta P$.

TABLE 1. Re-evaluation of the obtained optimal Pareto front using CFD

\begin{tabular}{lcccccc}
\hline \multirow{2}{*}{ Point } & \multicolumn{2}{c}{ Pressure drop $($ bar $)$} & \multicolumn{3}{c}{ Deformation $(\boldsymbol{\mu m})$} \\
\cline { 2 - 7 } & Pareto & CFD & $\begin{array}{c}\text { Error } \\
(\boldsymbol{\%})\end{array}$ & Pareto & CFD & $\begin{array}{c}\text { Error } \\
(\%)\end{array}$ \\
\hline$A$ & 8.86 & 8.96 & 1.18 & 3.15 & 3.24 & 2.88 \\
$B$ & 10.03 & 9.81 & -2.16 & 5.12 & 5.23 & 2.13 \\
$C$ & 10.09 & 10.28 & 1.89 & 7.50 & 7.40 & -1.32 \\
$D$ & 11.30 & 11.63 & 2.92 & 12.99 & 13.38 & 2.98 \\
$E$ & 11.52 & 11.73 & 1.82 & 19.11 & 18.90 & -1.11 \\
\hline
\end{tabular}

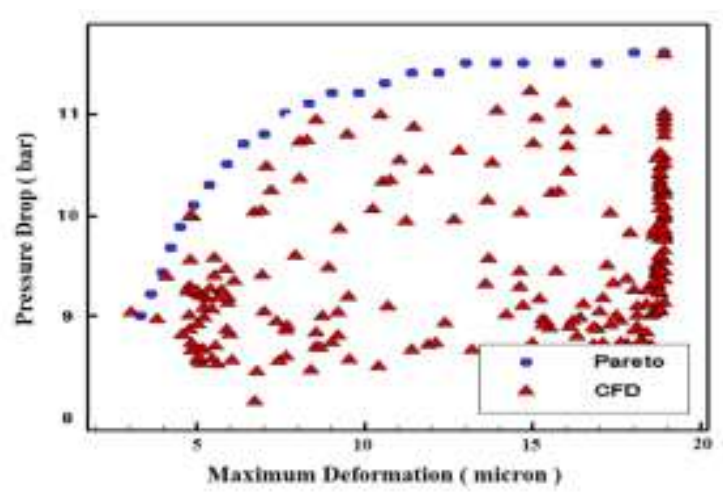

Figure 11. Overlapping of numerical results and the Pareto front that indicate the correctness of the optimization process

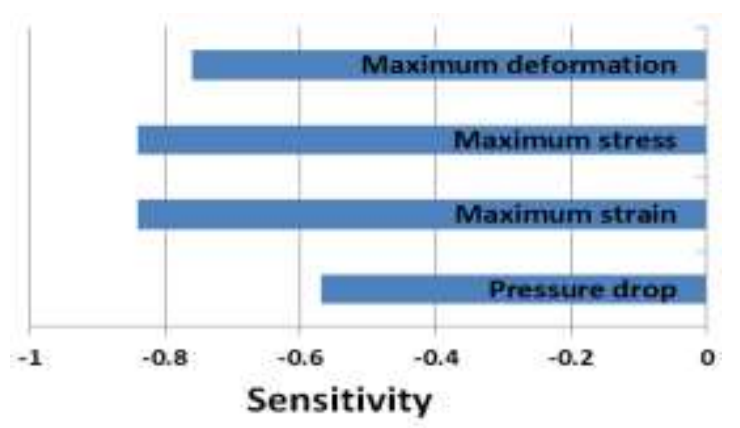

Figure 7. Sensitivity analysis results

TABLE 2. The values of objective functions and their associated design variables of the optimum points

\begin{tabular}{lccccc}
\hline & \multicolumn{2}{c}{$\begin{array}{c}\text { Design } \\
\text { variable }\end{array}$} & \multicolumn{4}{c}{ Objective functions } \\
\cline { 2 - 6 } Point & $\mathbf{D}(\mathbf{m m})$ & $\begin{array}{c}\text { Pressure } \\
\text { drop }(\text { bar })\end{array}$ & $\begin{array}{c}\text { Maximum } \\
\text { strain *10 }\end{array}$ & $\begin{array}{c}\text { Deformatio } \\
\mathbf{n}(\boldsymbol{\mu m})\end{array}$ & $\begin{array}{c}\text { Maximum } \\
\text { tension } \\
\left(\mathbf{N} / \mathbf{m}^{2}\right)^{*} \mathbf{1 0}^{6}\end{array}$ \\
\hline$A$ & 41.94 & 8.86 & 30.0 & 3.15 & 6.0 \\
\hline
\end{tabular}




\begin{tabular}{cccccc}
\hline$B$ & 41.76 & 10.03 & 30.8 & 5.12 & 6.1 \\
$C$ & 39.39 & 10.09 & 47.9 & 7.50 & 9.5 \\
$D$ & 32.27 & 11.30 & 94.8 & 12.99 & 18.9 \\
$E$ & 26.07 & 11.52 & 126.9 & 19.11 & 25.3 \\
\hline
\end{tabular}

Moreover, optimum design point $B$ obtained in this paper exhibits an increase in deformation (about 12.3\%) in comparison with that of point $A$ whilst its pressure drop improves about $43.9 \%$, similarly optimum design point $D$ exhibits a decrease in pressure drop (about 8.2\%) in comparison with that of point $E$ whilst its deformation improves about $38.3 \%$.

\section{CONCLUSION}

Multi-hole orifices have better performance than singlehole orifices. In this paper, multi-objective optimization of multi-hole orifice function was performed using a FSI analysis and multi-objective genetic algorithm. In all numerical analysis, the governing equations of the structure for orifice and the governing equations for the fluid were carried out for the fluid around orifice. All calculations were made for a 16-hole orifice with circular holes. The design variable in the optimization process was the distance between the holes of the orifice and thus the amount of shrinkage or opening of the orifice geometry. The objective functions were the pressure drop created on the sides of the orifice, the deformation and tension created in the orifice structure, which should be maximized, minimized and minimized, respectively.

Also, the sensitivity analysis of the distance between the holes of orifice on the functional functions of the orifice was performed and it was observed that among the functional functions, the most sensitivity was tension and strain, and the least sensitivity was the drop in pressure relative to the changes in the distance between the holes of orifice.

\section{REFERENCES}

1. Standardization, I.O.f., "Measurement of fluid flow by means of pressure differential devices inserted in circular cross-section conduits running full: Mesure de débit des fluides au moyen d'apparils déprimogènes. Inseres dans des conduites en charge de section ciculaire. General principles and requirements, International Organization for Standardization, (2003).

2. Sowa, W., Kroll, J., Samuelsen, G. and Holdeman, J., "Optimization of orifice geometry for cross-flow mixing in a cylindrical duct", in 32nd Aerospace Sciences Meeting and Exhibit. (1994), 219.

3. Zhang, Q. and Bodony, D.J., "Numerical investigation and modelling of acoustically excited flow through a circular orifice backed by a hexagonal cavity", Journal of Fluid Mechanics, Vol. 693, (2012), 367-401, https://doi.org/10.1017/jfm.2011.537
4. Araoye, A.A., Badr, H.M. and Ahmed, W.H., "Dynamic behaviour of flow through multi-stage restricting orifices", in Proceedings of the 3rd International Conference on Fluid Flow, Heat and Mass Transfer (FFHMT'16). Ottawa, Canada, Citeseer. (2016), 161.

5. Gan, G. and Riffat, S.B., "Pressure loss characteristics of orifice and perforated plates", Experimental Thermal and Fluid Science, Vol. 14, No. 2, (1997), 160-165, https://doi.org/10.1016/s0894-1777(96)00041-6

6. Zhao, T., Zhang, J. and Ma, L., "A general structural design methodology for multi-hole orifices and its experimental application", Journal of Mechanical Science and Technology, Vol. 25, No. 9, (2011), 2237, https://doi.org/10.1007/s12206-0110706-3

7. Simpson, A. and Ranade, V.V., "Modelling of hydrodynamic cavitation with orifice: Influence of different orifice designs", Chemical Engineering Research and Design, Vol. 136, (2018), 698-711, https://doi.org/10.1016/j.cherd.2018.06.014

8. Rainsford, G., Aulakh, D.J.S. and Ciccarelli, G., "Visualization of detonation propagation in a round tube equipped with repeating orifice plates", Combustion and Flame, Vol. 198, (2018), 205221, https://doi.org/10.1016/j.combustflame.2018.09.015

9. Yu, S., Yin, B., Deng, W., Jia, H., Ye, Z., Xu, B. and Xu, H., "Internal flow and spray characteristics for elliptical orifice with large aspect ratio under typical diesel engine operation conditions", Fuel, Vol. 228, (2018), 62-73, https://doi.org/10.1016/j.fuel.2018.04.156

10. Zhang, J., Zou, D., Ta, N. and Rao, Z., "Numerical research of pressure depression in aerostatic thrust bearing with inherent orifice", Tribology International, Vol. 123, (2018), 385-396, https://doi.org/10.1016/j.triboint.2018.03.009

11. Shan, F., Liu, Z., Liu, W. and Tsuji, Y., "Effects of the orifice to pipe diameter ratio on orifice flows", Chemical Engineering Science, Vol. 152, (2016), 497-506, https://doi.org/10.1016/j.ces.2016.06.050

12. Wang, L.-Q., Ma, H.-H., Deng, Y.-X. and Shen, Z.-W., "On the detonation behavior of methane-oxygen in a round tube filled with orifice plates", Process Safety and Environmental Protection, Vol. 121, (2019), 263-270, https://doi.org/10.1016/j.psep.2018.11.002

13. Wen, J., Sun, Q., Sun, Z. and Gu, H., "The effect of multi-orifice plate configuration on bubble detachment volume", Chinese Journal of Chemical Engineering, Vol. 27, No. 1, (2019), 72 84, doi. https://doi.org/10.1016/j.cjche.2018.09.024

14. Wang, L.-Q., Ma, H.-H. and Shen, Z.-W., "Effect of orifice plates on detonation propagation in stoichiometric hydrogen-oxygen mixture", Experimental Thermal and Fluid Science, Vol. 99, (2018), 367-373, https://doi.org/10.1016/j.expthermflusci.2018.08.012

15. Golijanek-Jędrzejczyk, A., Świsulski, D., Hanus, R., Zych, M. and Petryka, L., "Uncertainty of the liquid mass flow measurement using the orifice plate", Flow Measurement and Instrumentation, Vol. 62, (2018), 84-92, doi https://doi.org/10.1016/j.flowmeasinst.2018.05.012

16. Araoye, A., Badr, H., Ahmed, W., Habib, M. and Alsarkhi, A., "Erosion of a multistage orifice due to liquid-solid flow", Wear, Vol. 390, 2017), 270-282, https://doi.org/10.1016/j.wear.2017.07.010

17. Zhao, X., Wang, G., Lu, W., Chen, M., Yan, P. and Zhou, C., "Effects of close proximity underwater explosion on the nonlinear dynamic response of concrete gravity dams with orifices", Engineering Failure Analysis, Vol. 92, (2018), 566-586, https://doi.org/10.1016/j.engfailanal.2018.06.016

18. Qiao, M., Wei, W., Huang, W., Li, J., Xue, Y. and Deng, C., "Flow patterns and hydrodynamic model for gas-liquid co-current downward flow through an orifice plate", Experimental Thermal 
and Fluid Science, Vol. 100, (2019), 144-157, https://doi.org/10.1016/j.expthermflusci.2018.09.005

19. Zhao, D., Sun, Y., Ni, S., Ji, C. and Sun, D., "Experimental and theoretical studies of aeroacoustics damping performance of a bias-flow perforated orifice", Applied Acoustics, Vol. 145, (2019), 328-338, https://doi.org/10.1016/j.apacoust.2018.10.025

20. Rydlewicz, W., Rydlewicz, M. and Pałczyński, T., "Experimental investigation of the influence of an orifice plate on the pressure pulsation amplitude in the pulsating flow in a straight pipe", Mechanical Systems and Signal Processing, Vol. 117, (2019), 634-652, https://doi.org/10.1016/j.ymssp.2018.08.005

21. Araoye, A.A., Badr, H.M. and Ahmed, W.H., "Investigation of flow through multi-stage restricting orifices", Annals of Nuclear Energy, Vol. 104, (2017), 75-90, https://doi.org/10.1016/j.anucene.2017.02.002

22. Khalkhali, A. and Safikhani, H., "Pareto based multi-objective optimization of a cyclone vortex finder using cfd, gmdh type neural networks and genetic algorithms", Engineering Optimization, Vol. 44, No. 1, (2012), 105-118, https://doi.org/10.1080/0305215x.2011.564619

23. Safikhani, H., Akhavan-Behabadi, M., Nariman-Zadeh, N. and Abadi, M.M., "Modeling and multi-objective optimization of square cyclones using cfd and neural networks", Chemical
Engineering Research and Design, Vol. 89, No. 3, (2011), 301309, doi. https://doi.org/10.1016/j.cherd.2010.07.004

24. Sanaye, S. and Hajabdollahi, H., "Thermal-economic multiobjective optimization of plate fin heat exchanger using genetic algorithm", Applied Energy, Vol. 87, No. 6, (2010), 1893-1902, doi. https://doi.org/10.1016/j.apenergy.2009.11.016

25. Sanaye, S. and Dehghandokht, M., "Modeling and multiobjective optimization of parallel flow condenser using evolutionary algorithm", Applied Energy, Vol. 88, No. 5, (2011), 1568-1577, doi. https://doi.org/10.1016/j.apenergy.2010.11.032

26. Yamini, O.A., Mousavi, S.H., Kavianpour, M.R. and Movahedi, A., "Numerical modeling of sediment scouring phenomenon around the offshore wind turbine pile in marine environment", Environmental Earth Sciences, Vol. 77, No. 23, (2018), 1-15, doi. https://doi.org/10.1007/s12665-018-7967-4

27. Sengupta, A.R., Gupta, R. and Biswas, A., "Computational fluid dynamics analysis of stove systems for cooking and drying of muga silk", Emerging Science Journal, Vol. 3, No. 5, (2019), 285-292, doi. https://doi.org/10.28991/esj-2019-01191

28. Dirbude, S.B. and Maurya, V.K., "Effect of uniform magnetic field on melting at various rayleigh numbers", Emerging Science Journal, Vol. 3, No. 4, (2019), 263-273, doi: 10.28991/esj-201901189. 